\title{
Space Assembly of Large Structural System Architectures (SALSSA)
}

\author{
John T. Dorsey \\ Judith J. Watson
NASA Langley Research Center
Hampton, VA 23681

\begin{abstract}
Developing a robust capability for Space Assembly of Large Spacecraft Structural System Architectures (SALSSA) has the potential to drastically increase the capabilities and performance of future space missions and spacecraft while significantly reducing their cost. Currently, NASA architecture studies and space science decadal surveys identify new missions that would benefit from SALSSA capabilities, and the technologies that support SALSSA are interspersed throughout the fourteen NASA Technology Roadmaps. However, a major impediment to the strategic development of cross-cutting SALSSA technologies is the lack of an integrated and comprehensive compilation of the necessary information. This paper summarizes the results of a small study that used an integrated approach to formulate a SALSSA roadmap and associated plan for developing key SALSSA technologies.
\end{abstract}

\section{Nomenclature}

$\begin{array}{ll}\text { ATLAST } & \text { Advanced Technology Large Aperture Space Telescope } \\ \text { DOD } & \text { Department of Defense } \\ \text { DRM } & \text { Design Reference Mission } \\ \text { E-Beam } & \text { Electron-Beam (welding) } \\ \text { EMC } & \text { Evolvable Mars Campaign } \\ \text { EVA } & \text { Extra-Vehicular Activity } \\ \text { GCDP } & \text { Game Changing Development Program } \\ \text { GSFC } & \text { Goddard Space Flight Center } \\ \text { IPJR } & \text { Intelligent Precision Jigging Robot } \\ \text { ISA } & \text { In-Space Assembly } \\ \text { ISRU } & \text { In-Situ Resource Utilization } \\ \text { ISS } & \text { International Space Station } \\ \text { IVA } & \text { Intra-Vehicular Activity } \\ \text { JWST } & \text { James Webb Space Telescope } \\ \text { SALSSA } & \text { Space Assembly of Large Space Architectures } \\ \text { SOA } & \text { State-of-the-art } \\ \text { SRMS } & \text { Shuttle Remote Manipulator System } \\ \text { SSRMS } & \text { Space Station Remote Manipulator System } \\ \text { STMD } & \text { Space Technology Mission Directorate } \\ \text { TA } & \text { Technology Area } \\ \text { TALISMAN } & \text { Tendon-Actuated Lightweight In-Space MANipulator }\end{array}$

1john.t.dorsey@nasa.gov 


\section{Introduction}

Except for the International Space Station (ISS), all current spacecraft are transported to orbit as an integrated unit using a single launch. This severely constrains the mass and size of the spacecraft system because the spacecraft must be designed to meet: the mass constraint of the chosen launch vehicle, the volume constraint of the launch vehicle payload shroud, and the loads imposed by the launch environment. Once in space, various systems, such as solar arrays, radiators, and antennas are deployed to achieve an operational configuration. One example, the James Webb Space Telescope ${ }^{1}$ (JWST), with a primary mirror diameter of 6.5 meters, likely represents an upper limit to the size of aperture that can be achieved for a single-launch telescope using deployable structures and mechanisms. As the spacecraft complexity rapidly increases with increasing number of deployable mechanisms and systems, so does the potential for deployment failure, resulting in a decrease in spacecraft and mission reliability. Although an on-orbit servicing and repair capability, as illustrated in Figure 1 for a large space telescope, would help to mitigate spacecraft mission risk resulting from deployment and other early system failures, this capability does not currently exist. Furthermore, current spacecraft, including the JWST, are not designed to take advantage of such services even if they did exist. One alternative is to increase the payload shroud volume on future heavy lift launch vehicles. However, this approach only marginally increases the spacecraft size limit and still does nothing to enable servicing and repair capability.

Figure 1. Servicing large space telescope using robotic spacecraft and manipulators.

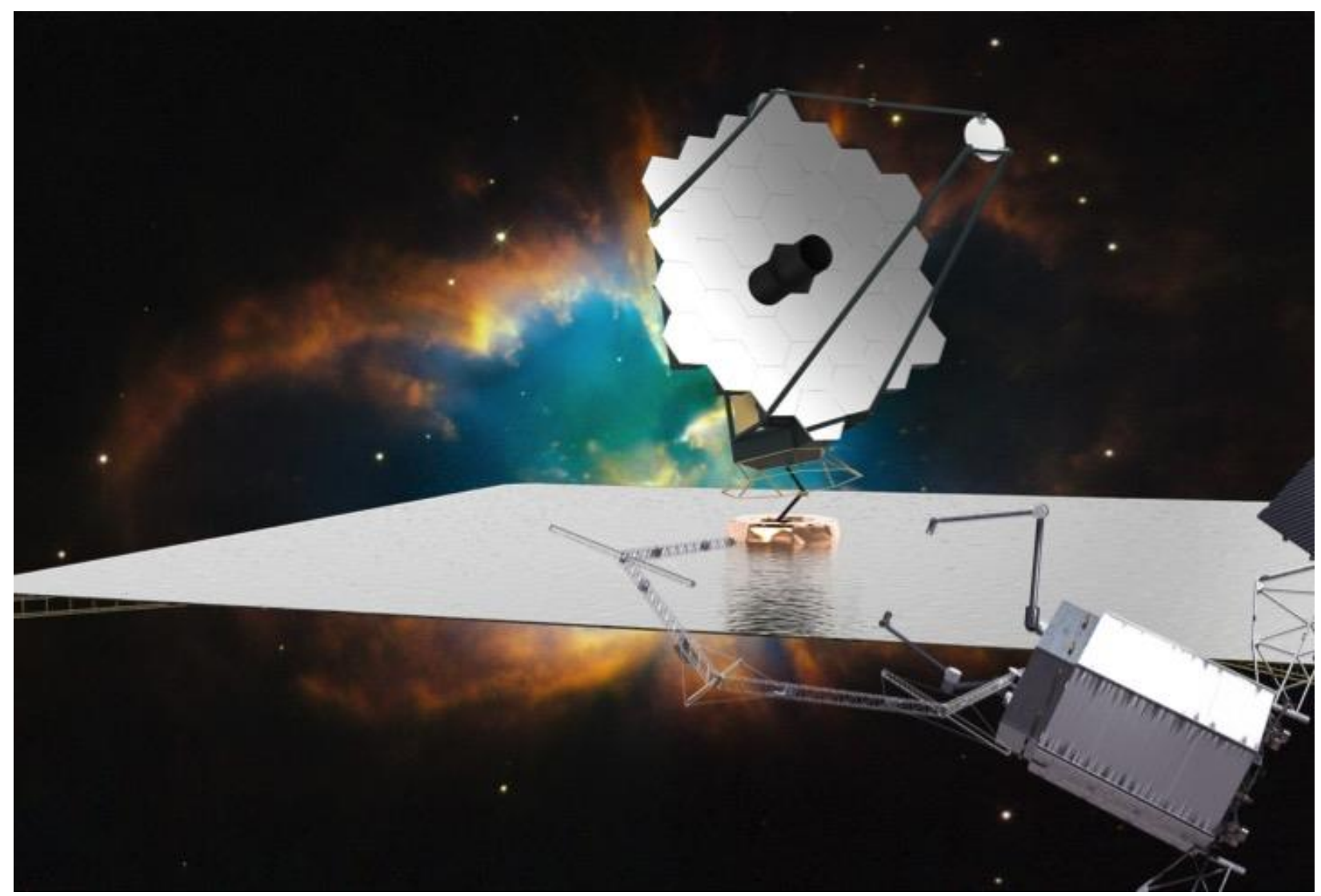


A more innovative and potentially less costly approach that can result in much larger space systems is to incorporate in-space assembly (ISA), similar to the approach used for the ISS ${ }^{2}$, while leveraging the variety of launch vehicles and multiple launches available. The ISS was assembled from a relatively small number of very large and massive modules and components, requiring several launches over multiple years. The components were positioned and berthed tele-robotically on orbit, and then permanent mechanical and utility line connections were completed by extra vehicular activity (EVA) astronauts. The ISS represents a large space system that was assembled on orbit, but that assembly capability ended with the retirement of the Space Shuttle.

For in-space robotic operations, the capability to manipulate large masses was present with the Shuttle Remote Manipulator System ${ }^{3}$ and the Space Station Remote Manipulator System (SRMS and SSRMS), but the SRMS capability is no longer available and the SSRMS is limited to a single facility, in a specific orbit, with many restrictions imposed by NASA-ISS requirements. The Dextre ${ }^{4}$ robot, a smaller, multi-armed dexterous manipulator, is externally located on the ISS and is currently supporting Goddard Space Flight Center (GSFC) satellite servicing experiments. The SRMS, SSRMS, and Dextre are all traditional manipulator architectures, consisting of lightweight booms connected by massive rotary joints that account for $85-90$ percent of the manipulator mass and compliance. The long booms result in restrictive packaging options, and adding joints to improve packaging volume would incur an extremely high mass penalty. The high mass and compliant joints also result in limits to reach and stiffness.

However, many other applications can benefit from on-orbit assembly ${ }^{5}$ of lightweight structural elements and modular units, including: a large telescope, large (megawatt) solar arrays, and exploration vehicle applications. On-orbit assembly enables efficient construction of large area or span trusses to provide lightweight, high-stiffness, precise support and backbone structures for these systems. Previous approaches proposed for ISA of truss and telescope structures and systems were perceived as very costly because they required: highly precise and complex mechanisms, supporting infrastructure unique to each application, robust processes for other operations (such as mirror-to-truss assembly), and typically incorporated EVA in the assembly process.

In Fiscal Year 2015, the NASA Game Changing Development Program (GCDP), a part of the Space Technology Mission Directorate (STMD), sponsored a small study to investigate and define the technologies needed to enable Space Assembly of Large Structural System Architectures (SALSSA). The goal of SALSSA is to enable a new integrated space assembly paradigm, first introduced in Reference 6 that substantially improves the performance, while lowering the cost and risk of future missions. This new paradigm simultaneously includes and integrates: the spacecraft/space-system architecture, assembly operations, infrastructure for robotic servicing and assembly, new structural concepts and structural joining methods, and integration of secondary systems/wiring/etc.

The first part of the study involved reviewing current NASA Mission Architecture Studies $^{7,8}$, Space Science Decadal Surveys ${ }^{9,10}$ and Technology Area Roadmaps ${ }^{11}$. Although modular systems, on-orbit assembly, and in-space servicing are discussed at various levels in these separate documents, there is no comprehensive and single compilation of these capabilities and the technologies required to support them as represented by the SALSSA approach. For example, major mission applications and technology needs for autonomous robotic in-space servicing and

3john.t.dorsey@nasa.gov 
assembly are scattered throughout the Structures and Materials, Robotics and Automation, and Space Science roadmaps. Thus, the SALSSA roadmap was created by extracting applicable information and compiling the information into a comprehensive roadmap that specifically addresses autonomous robotic ISA. The SALSSA roadmap shows a proposed plan for phasing the SALSSA approach into future missions such as those described in Reference 5. From that phasing, representative missions and definitions of their systems are selected, and improvements to mission function that are enabled by the SALSSA approach are identified. A fundamental set of the SALSSA Capability Areas are then identified and defined that are versatile across all applicable missions and architectures.

The second part of the study selected three focus applications to represent desired NASA mission capabilities that can best be achieved by incorporating the SALSSA approach. These focus applications represent complete mission systems and are: 1) a megawatt class solar electric tug ${ }^{12}$, 2) a nominally 20-meter diameter (main aperture) next generation space telescope ${ }^{3}$, such as the Advanced Technology Large Aperture Space Telescope (ATLAST) ${ }^{13}$, and, 3) repair, replacement and repurposing of major systems modules for the Evolvable Mars Campaign (EMC) spacecraft systems ${ }^{14}$. For each focus application, a notional large structural system architecture is defined, concepts are developed for discretizing the system into modules that can be orbited by existing launch vehicles, and a concept of operations is developed for robotically assembling the systems in space. From this information, Cross-Cutting Technical Capabilities are identified, that when developed and implemented, would leverage robotic space assembly to field not only the three focus mission systems, but a significant number of other NASA, commercial and Department of Defense (DOD) missions. Finally, from the set of technical capabilities, examples of specific technologies that enable those capabilities are identified. The SALSSA roadmap, the SALSSA approach to the three focus applications, and the identified cross-cutting technical capabilities are presented in this paper.

\section{Space Assembly Roadmap and Capabilities Needed}

NASA performs Mission Architecture Studies ${ }^{7,8}$ and Space Science Decadal Surveys ${ }^{9,10}$ to examine and identify new capabilities that are needed for future missions. The space systems proposed to achieve these new mission capabilities, in turn, generally require that new technologies be developed that increase some measure of performance or reduce some measure of cost. In 2012, NASA developed a set of fourteen technology roadmaps ${ }^{11}$ that documented a wide range of candidates for these new capabilities and technologies. The NASA technology roadmaps were updated and expanded in 2015.

As noted previously in this paper, ISA has been identified as a recurring capability in architecture and decadal studies ${ }^{15,16,17,18}$ needed for the elements and systems to make future missions successful. The notional SALSSA roadmap proposed here is an attempt to:

1) Define ISA capabilities and elements for categorizing technology needs.

2) Identify NASA Technology Area (TA) roadmap capabilities and technologies that would either enable ISA or could benefit from the ISA capability.

3) Compile TA referenced ISA technologies and associated NASA missions and proposed mission dates to suggest ISA technology needs. 
Since both the EMC and the Science Missions will continue to evolve as planning, trade studies, and technologies advance, this roadmap attempts to provide a summary of missions and architectures being proposed at this point in time (2016).

\section{SALSSA Definition, Capabilities, and Elements}

Developing SALSSA capabilities will enable the assembly or construction of spacecraft or space system components by joining the system components through a variety of methods. This includes the ability to disassemble or deconstruct the system and then reconfigure those systems/components into a new system or craft. SALSSA would support reusability and mission adaptability while also enhancing the operational flexibility for human exploration and science missions, and commercial operations in space. SALSSA capabilities are achieved by integrating elements from across technologies areas such as robotics and autonomy, structures, mechanisms, manufacturing, fabrication, in-situ resource utilization (ISRU), communication, and computing.

SALSSA is divided into four key capability areas: assembly and construction, servicing and repair, repurpose refurbish and recycle, and in-situ manufacturing, as defined in Table 1.

Table 1. SALSSA Key Capability Areas.

\begin{tabular}{|l|l|}
\hline Capability Area & \multicolumn{1}{c|}{ Definition } \\
\hline $\begin{array}{l}\text { Assembly/ } \\
\text { Construction }\end{array}$ & $\begin{array}{l}\text { The capability to assemble or construct spacecraft or space system } \\
\text { components by joining components through a variety of methods. This also } \\
\text { includes the capability to disassemble or deconstruct the system and } \\
\text { reconfigure it into a new system or spacecraft. }\end{array}$ \\
\hline Servicing/ Repair & $\begin{array}{l}\text { The capability to repair, upgrade, enhance a spacecraft or system to enable it } \\
\text { to continue to be functional or improve its function, through replacing old } \\
\text { components with new components or repairing the damaged component. }\end{array}$ \\
\hline $\begin{array}{l}\text { Repurposing/ } \\
\text { Refurbishing/ }\end{array}$ & $\begin{array}{l}\text { The capability to redefine the purpose of the system by improving, } \\
\text { upgrading, reconfiguring and/or reusing modular components. }\end{array}$ \\
\hline $\begin{array}{l}\text { In-situ } \\
\text { Manufacturing }\end{array}$ & $\begin{array}{l}\text { The capability to manufacture spacecraft systems/components at the } \\
\text { spacecraft operational location (in space). Manufacturing feedstock could be } \\
\text { provided by launch (from Earth, Moon, asteroids, etc.), direct ISRU or } \\
\text { recycling. }\end{array}$ \\
\hline
\end{tabular}

Each Key Capability Area requires a supporting set of common or overlapping Technology Elements, as illustrated in Figure 2. Technologies within these elements that are used for one Capability Area will generally be cross-cutting to all of the other capabilities. For example, a robotic system that would assemble a spacecraft could also be used to: effect servicing and repairs, reconfigure the spacecraft at a later time, or build a completely different spacecraft, thus cutting across many different NASA missions. Most of the technologies needed to enable these key capabilities can be grouped under the following technology elements: modularity, autonomous operations, manipulation systems, metrology and verification, and on-site infrastructure. Definitions of the five technology elements are shown in Table 2. 


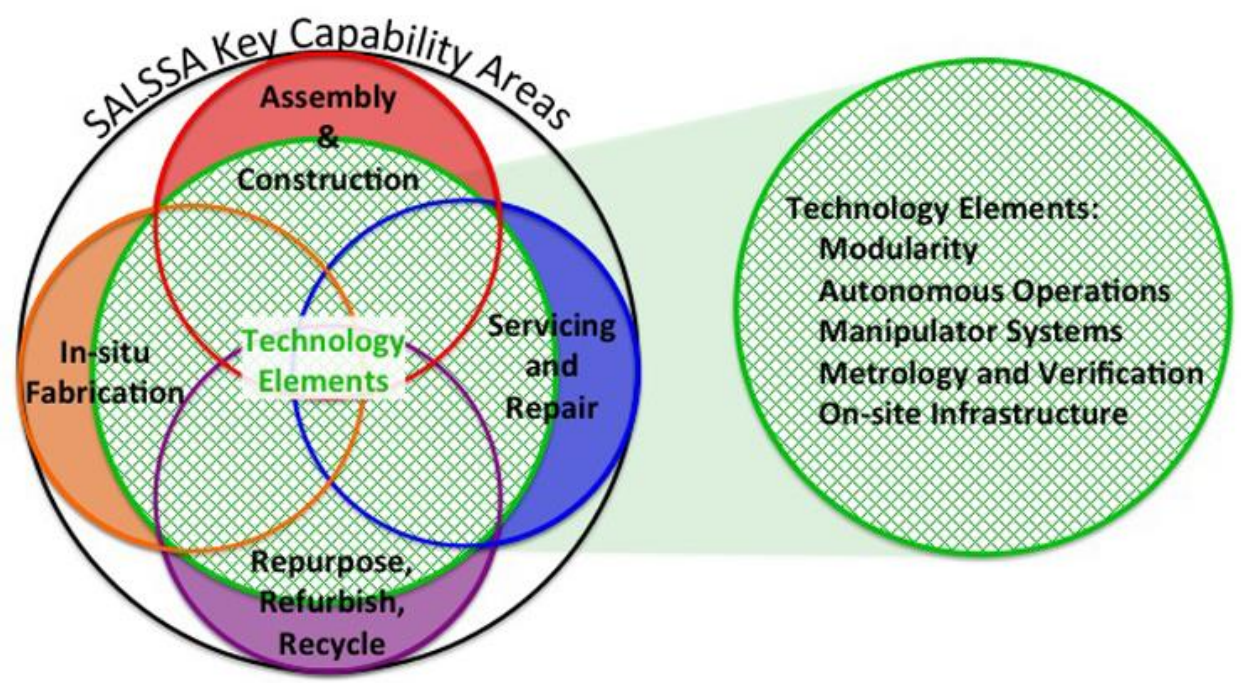

Figure 2. ISA Capabilities and Elements

Table 2. SALSSA Technology Elements.

\begin{tabular}{|l|l|}
\hline Element & Definition \\
\hline Modularity & $\begin{array}{l}\text { Technologies needed to enable modular, and where possible, interchangeable } \\
\text { components of spacecraft and spacecraft systems at appropriate levels of the } \\
\text { spacecraft architecture. Includes individual components to system components, } \\
\text { to self-contained units and the interfaces that join them together. }\end{array}$ \\
\hline $\begin{array}{l}\text { Autonomous } \\
\text { Operations }\end{array}$ & $\begin{array}{l}\text { The automation and informational technologies needed to enable the action of } \\
\text { an automated or robotic system to perform the needed capabilities. }\end{array}$ \\
\hline $\begin{array}{l}\text { Manipulation } \\
\text { Systems }\end{array}$ & $\begin{array}{l}\text { Technology systems that physically move, position, engage, disengage, and/or } \\
\text { enable the manipulation of components and spacecraft. Examples include } \\
\text { moving and handling objects, assembling, excavating, grappling, and berthing. }\end{array}$ \\
\hline $\begin{array}{l}\text { Metrology and } \\
\text { Verification }\end{array}$ & $\begin{array}{l}\text { Technologies that allow for verification and confirmation of the assembled or } \\
\text { repaired spacecraft's required geometries and performance. }\end{array}$ \\
\hline $\begin{array}{l}\text { On-site } \\
\text { Infrastructure }\end{array}$ & $\begin{array}{l}\text { Infrastructure needed at the site of the assembly operation to support functions } \\
\text { such as module aggregation, storage and staging. Also, other infrastructure } \\
\text { that can be used to support more than one operation and mission. }\end{array}$ \\
\hline
\end{tabular}

\section{SALSSA Capabilities Identified in TA Roadmaps}

The NASA Technology Roadmaps ${ }^{11}$ are "a set of documents that consider a wide range of needed technology candidates and development pathways for the next 20 years (2015-2035)." They provide descriptions of 15 technology areas, the related capabilities needed, and the proposed technologies that would fill gaps in those needs. In addition, the technologies are mapped against planned and reference missions for exploration, science and aeronautics. The SALSSA capability would benefit from technologies being considered for development in the current technology roadmaps as well as provide capabilities the roadmaps also recommend being developed. Currently defined NASA technology areas having capabilities and technologies that appear to correspond to those in SALSSA are:

- TA02 In-Space Propulsion Technologies, 
- TA03 Space Power and Energy Storage,

- TA04 Robotics and Autonomous Systems,

- TA05 Communications, Navigation, and Orbital Debris Tracking and Characterization Systems,

- TA07 Human Exploration Destination Systems,

- TA08 Science Instruments, Observatories, and Sensor Systems,

- TA11 Modeling simulation information technology and Processing, and

- TA12 Materials, Structures, Mechanical Systems, and Manufacturing.

The NASA Roadmap Technology Areas are mapped in Table 3 in terms of capabilities, technologies and applications to SALSSA Technology Elements. In some cases, for example, 4.3 - Robotics and Autonomous Systems - Manipulation, roadmap technologies would enable (support) SALSSA robotic and autonomous operations requiring manipulation of spacecraft components, while in other cases, 8.2.2.2 - Science Instruments, Observatories, and Sensor Systems - Erectable Structure, for example, the application would benefit from having the SALSSA capabilities and technologies.

Table 3. SALSSA Technology Elements map to NASA Technology Areas

\begin{tabular}{|c|c|}
\hline $\begin{array}{l}\text { SALSSA } \\
\text { Technology } \\
\text { Flement }\end{array}$ & $\begin{array}{l}\text { NASA Roadmap Technology Areas: Capabilities and } \\
\text { Technologies }\end{array}$ \\
\hline Modularity & $\begin{array}{ll}\text { Applications } \\
\text { 2.4.2 } & \text { Propellant Storage and Transfer } \\
\text { 3.1.3.2 } & \text { Solar Arrays } 250 \mathrm{kw} \\
3.1 .3 .3 & \text { Solar Arrays MW } \\
\text { 5.1.2 } & \text { Optical Communications and Navigation - Large apertures } \\
\text { 8.2 } & \text { Observatories } \\
& \\
\text { Element } & \text { Technologies } \\
3.1 .3 .2 & \text { Solar arrays } 250 \mathrm{kw} \\
4.7 .1 & \text { Modularity, Commonality, Interfaces } \\
\text { 7.6.6 } & \text { (Destination Systems) Construction and Assembly } \\
8.2 .2 .1 & \text { (Observatories) Deployable Structure } \\
\text { 8.2.2.2 } & \text { (Observatories) Erectable Structure } \\
\text { 12.2.1.4 } & \text { Very Large Solar Array Structure } \\
\text { 12.2.1.5 } & \text { Precision Expandable Structure } \\
\text { 12.2.5.4 } & \text { Reusable Modular component } \\
\text { 12.3.1 } & \text { Deployables, docking and interfaces } \\
\text { 12.3.2 } & \text { Mechanisms Life Extension Systems (harsh environments) }\end{array}$ \\
\hline $\begin{array}{l}\text { Autonomous } \\
\text { Operations }\end{array}$ & $\begin{array}{ll}\text { Applications } \\
\text { 2.4.2 } & \text { Propellant Storage and Transfer } \\
3.1 .3 .2 & \text { Solar arrays } 250 \mathrm{kw} \\
\text { 3.1.3.3 } & \text { Solar arrays MW } \\
\text { 3.1.3.4 } & \text { Retractable solar arrays } \\
\text { 5.1.2 } & \text { Optical Communications and Navigation - Large apertures } \\
\text { 7.1.2.6 } & \text { ISRU - E-Beam Freeform Fabrication }\end{array}$ \\
\hline
\end{tabular}




\begin{tabular}{|c|c|c|}
\hline & $\begin{array}{l}\text { Elemen } \\
4.1 \\
4.4 \\
4.5 \\
4.6 \\
4.7 \\
5.3 \\
11.1 .1\end{array}$ & $\begin{array}{l}\text { Human Exploration Destination Systems-Sustainability and } \\
\text { Supportability (Repair and Maintenance) } \\
\text { Human Exploration Destination Systems-Construction and } \\
\text { Assembly } \\
\text { Observatories } \\
\text { Manufacturing Processes (ISA, Fabrication, and Repair } \\
\text { process) } \\
\text { Technologies } \\
\text { Sensing and Perception } \\
\text { Human-Systems Interaction } \\
\text { System Level Autonomy } \\
\text { Autonomous Rendezvous and Docking } \\
\text { Robotics and Autonomous Systems -Systems Engineering } \\
\text { Communications... -Internetworking } \\
\text { Flight computing }\end{array}$ \\
\hline $\begin{array}{l}\text { Manipulation } \\
\text { Systems }\end{array}$ & $\begin{array}{l}\text { Applica } \\
2.4 .2 \\
3.1 .3 .2 \\
3.1 .3 .3 \\
4.6 \\
5.1 .2 \\
7.1 .2 .6 \\
7.2 \\
7.6 .6 \\
\\
8.2 \\
\text { Elemen } \\
4.1 \\
4.3 \\
12.3 .2 \\
12.3 .3\end{array}$ & $\begin{array}{l}\text { ions } \\
\text { Propellant Storage and Transfer } \\
\text { Solar arrays } 250 \mathrm{kw} \\
\text { Solar arrays MW } \\
\text { Rendezvous and Docking } \\
\text { Optical Communications and Navigation - Large apertures } \\
\text { ISRU - E-Beam Freeform Fabrication } \\
\text { Human Exploration Destination Systems-Sustainability and } \\
\text { Supportability (Repair and Maintenance) } \\
\text { Human Exploration Destination Systems-Construction and } \\
\text { Assembly } \\
\text { Observatories } \\
\text { Technologies } \\
\text { Sensing and Perception } \\
\text { Manipulation } \\
\text { Mechanisms Life Extension Systems (harsh environments) } \\
\text { Electro-mechanical, Mechanical, and Micromechanisms }\end{array}$ \\
\hline $\begin{array}{l}\text { Metrology and } \\
\text { Verification }\end{array}$ & $\begin{array}{l}\text { Applica } \\
2.4 .2 \\
3.1 .3 .2 \\
3.1 .3 .3 \\
3.1 .3 .4 \\
4.6 \\
5.1 .2 \\
7.1 .2 .6 \\
7.2 \\
7.6 .6\end{array}$ & $\begin{array}{l}\text { ions } \\
\text { Propellant Storage and Transfer } \\
\text { Solar arrays } 250 \mathrm{kw} \\
\text { Solar arrays MW } \\
\text { Retractable solar arrays } \\
\text { Rendezvous and Docking } \\
\text { Optical Communications and Navigation - Large apertures } \\
\text { ISRU - E-Beam Freeform Fabrication } \\
\text { Human Exploration Destination Systems-Sustainability and } \\
\text { Supportability (Repair and Maintenance) } \\
\text { Human Exploration Destination Systems-Construction and } \\
\text { Assembly }\end{array}$ \\
\hline
\end{tabular}




\begin{tabular}{|l|ll|}
\hline & 8.2 & Observatories \\
& 12.2.1.5 & Precision expandable structures \\
& 12.4.1.4 & ISA, fabrication, and repair \\
& \multicolumn{3}{|c|}{ Element } & Technologies \\
& 4.1 & Sensing and Perception \\
& 4.7 & Robotics and Autonomous Systems -Systems Engineering \\
& 5.3 & Communications \\
& 11.1 .1 & Flight computing \\
\hline On-site & Applications \\
& 2.4 .2 & Propellant Storage and Transfer \\
& 3.1 .3 .3 & Solar arrays MW \\
& 7.1 .2 .6 & ISRU - E-Beam Freeform Fabrication \\
& 7.2 & Human Exploration Destination Systems-Sustainability and \\
& \multicolumn{3}{|c|}{ Supportability (Repair and Maintenance) } \\
& 7.6.6 & Human Exploration Destination Systems-Construction and \\
& Assembly \\
& 8.2 & Observatories \\
& 12.4 .1 .4 & ISA, fabrication, and repair \\
\hline
\end{tabular}

\section{SALSSA and NASA Missions}

Reviewing EMC studies and Decadal Science surveys cited previously, examples of some proposed space systems that require or benefit from SALSSA capabilities were identified and are listed in Table 4.

Table 4. SALSSA Capability needs for future mission systems.

\begin{tabular}{|l|l|l|l|}
\hline \multicolumn{1}{|c|}{ System } & \multicolumn{1}{c|}{ Mission } & \multicolumn{1}{c|}{$\begin{array}{c}\text { Mission improved } \\
\text { function }\end{array}$} & \multicolumn{1}{c|}{$\begin{array}{c}\text { SALSA Capabilities } \\
\text { needed }\end{array}$} \\
\hline $\begin{array}{l}\text { Large, } \\
25-\text {-meter } \\
\text { diameter } \\
\text { Telescope }\end{array}$ & $\begin{array}{l}\text { Astrophysics/ } \\
\text { search for planets }\end{array}$ & $\begin{array}{l}\text { Increased diameter to } \\
\text { improve telescope } \\
\text { resolution }\end{array}$ & $\begin{array}{l}\text { Assembly/ Servicing/ } \\
\text { Repair/ Refurbishment }\end{array}$ \\
\hline $\begin{array}{l}250 \mathrm{Kw} \text { to } \\
\text { 1000 Kw solar } \\
\text { arrays }\end{array}$ & $\begin{array}{l}\text { Solar electric } \\
\text { propulsion, transit } \\
\text { vehicles }\end{array}$ & $\begin{array}{l}\text { Increased power for } \\
\text { spacecraft transit and at } \\
\text { Mars (destination) }\end{array}$ & $\begin{array}{l}\text { Assembly/ Servicing/ } \\
\text { Repair/ Refurbishment/ } \\
\text { Repurposing }\end{array}$ \\
\hline $\begin{array}{l}\text { Multi-module } \\
\text { Vehicles }\end{array}$ & $\begin{array}{l}\text { Mars Crew } \\
\text { Transit vehicles, }\end{array}$ & $\begin{array}{l}\text { Exploration } \\
\text { missions/Science } \\
\text { missions (vehicles too } \\
\text { large for single launch }\end{array}$ & $\begin{array}{l}\text { Assembly/ Servicing/ } \\
\text { Repair/ Refurbishment }\end{array}$ \\
\hline $\begin{array}{l}\text { In-Space } \\
\text { Aggregation } \\
\text { Facilities }\end{array}$ & $\begin{array}{l}\text { Explos gravity } \\
\text { Science, Fuel } \\
\text { depots }\end{array}$ & $\begin{array}{l}\text { Facility for } \\
\text { assembly/servicing/repair } \\
\text { in Cis-lunar space }\end{array}$ & $\begin{array}{l}\text { Assembly/ Servicing/ } \\
\text { Repair/ Refurbishment/ } \\
\text { Repurposing/in-situ } \\
\text { Manufacturing }\end{array}$ \\
\hline
\end{tabular}




\begin{tabular}{|l|l|l|l|}
$\begin{array}{l}\text { Planetary } \\
\text { Surface systems }\end{array}$ & $\begin{array}{l}\text { Habitation, ISRU, } \\
\text { Mars surface } \\
\text { systems }\end{array}$ & $\begin{array}{l}\text { Improve launch vehicle } \\
\text { options, base setup for } \\
\text { crew, large system } \\
\text { aggregation on surface }\end{array}$ & $\begin{array}{l}\text { Assembly/ Servicing/ } \\
\text { Repair/ Refurbishment/ } \\
\text { Repurposing/ in-situ } \\
\text { Manufacturing }\end{array}$ \\
\hline
\end{tabular}

\section{Focus Applications}

Three focus applications have been chosen that represent desired NASA mission capabilities, but which can best be achieved by incorporating some degree of on-orbit assembly. The focus applications represent complete mission systems and are: 1) a megawatt class solar electric tug ${ }^{12}$; 2) a nominally 20 -meter diameter (main aperture) next generation space telescope such as the ATLAST ${ }^{13}$, and; 3) repair, replacement and repurposing of major systems modules that form an aggregation site at Earth-Moon L2 and the spacecraft that transports humans to Mars ${ }^{14}$. For each Focus Application, a series of challenges are listed, based on assuming a traditional architecture where the entire spacecraft is packaged and launched as a single integrated system that is deployed once on orbit. As an alternative for each Focus Application, a notional SALSSAbased architecture is defined, concepts are developed for discretizing the system into modules that can be orbited by existing launch vehicles, and a concept of operations is developed for robotically assembling the systems in space. From this information, Cross-Cutting Technical Capabilities are identified, that when developed and implemented, would leverage robotic space assembly to field not only the three focus mission systems, but a significant number of other NASA, Commercial and DOD missions.

\section{(1) Megawatt Class Solar Electric Tug}

Challenges. The tug consists of the spacecraft bus and two large solar array wings (Figure 3 ). The solar array wings would each supply from $250 \mathrm{kw}$ to $500 \mathrm{kw}$ of power to the ion engines. There are significant challenges to achieving the large area of solar arrays required in a single deployable system. The arrays must be designed with sufficient structural stiffness to meet a spacecraft fundamental frequency requirement of 0.1 hertz, and meet a strength requirement that can sustain a $0.1 \mathrm{~g}$ acceleration during boost using a chemical stage ${ }^{19}$.

ISA Concept. The solar array wings are composed of a backbone truss, onto which current stateof-the-art solar array modules (each $20 \mathrm{kw}$ to $30 \mathrm{kw}$ ) can be attached; the backbone truss and each individual solar array are considered to be modules. The backbone truss is sized so that the solar array wings meet the spacecraft stiffness and strength requirements. The backbone truss could be a single fold-deployable square (4-longeron) truss that has simple hinge joints and telescoping members in the diagonals. A long reach manipulator would deploy a pair of truss bays sequentially, intelligent precision jigging robots (IPJRs) would set the geometry of the truss bays, and the joints would be welded or bonded to achieve structural integrity. This concept eliminates all of the deployment motors, mechanisms, and latches associated with conventional deployable trusses, which reduces mass and complexity and increases reliability. A simple structural interface is preintegrated at evenly spaced locations on the truss where the solar array modules can be attached. A long-reach manipulator would position a solar array module near the truss interface; a set of IPJRs would grapple the module and locate and orient it perpendicular to, and in the center of the

10john.t.dorsey@nasa.gov 
truss face; the IPJRs would then hold the solar array module in place while another manipulator holding an electron beam (E-Beam) tool welds the structural connection. The solar array modules can be removed for replacement or upgrade at a later date because welding is a reversible joining process. The solar array module has an extension wiring bundle with a modular electrical/data interface. The manipulator plugs this into the pre-integrated central electrical/data wiring harness that runs down the interior of the backbone truss. Solar array module can be attached to each of the wing backbone trusses similarly in a repetitive process.

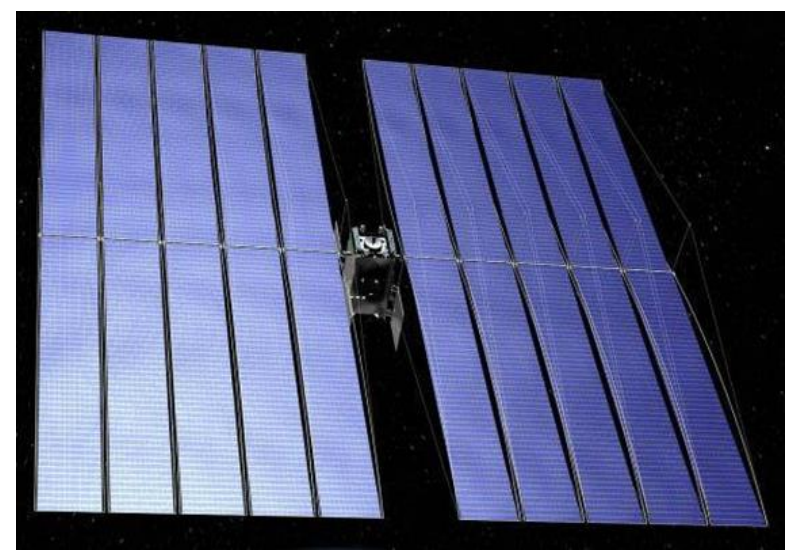

Figure 3. Example of megawatt class solar electric tug concept.

\section{(2) Large Next-Generation Space Telescope}

Challenges. The space telescope consists of a large diameter main aperture, secondary mirror, scientific instruments and a large sunshield (Figure 4). There are significant challenges to achieving the large aperture while maintaining high mirror surface precision and stability requirements. There are additional challenges in reliably deploying the large-expanse sunshield and in providing for system refueling, maintenance and instrument replacement and upgrades. Ground test of the complete system is challenging because of its large size and the desire to design for in service $(0 \mathrm{~g})$ loads as opposed to $1 \mathrm{~g}$ testing loads.

On Orbit Assembly Concept. The primary aperture would be assembled from a series of integrated modules including: support truss, mirrors, mirror mounting and control interfaces, power/data wiring, etc. These modules would be sized such that they can package in the volume of the chosen launch vehicle fairing, with the goal being to have a highly reliable, simple packaging concept. This size would allow each of the modules to be deployed for testing in current ground-based thermal vacuum facilities and validated, then packaged for launch. The module would include a deployable (2-D like Pactruss ${ }^{20}$ ) truss, to which all of the mirrors, electronics, power/data wiring, etc. are pre-integrated and the mirror surface precision set before launch. As modules are orbited, they could be aggregated at an assembly site anywhere in space. An assembly site could be a platform or a spacecraft bus that has robotic capabilities for; long-reach grappling and manipulation, dexterous manipulation, precision jigging, and joining (mechanical fastening, EBeam welding, bonding). The long-reach manipulator(s) and jigging robots would deploy each integrated telescope module and complete any required joining operations. As each module is deployed, the long-reach manipulator, in coordination with the jigging robots, would position and precisely align each module. A limited number of modular interfaces would be used for moduleto-module joining with the goal being to use a simple mechanical connector in conjunction with a 
separate data/power connector. After the jigging robots precisely align the modules, a long-reach manipulator with an appropriate joining end effector would complete the mechanical/welded/bonded joints. A metrology system that uses vision to interrogate module location/orientation is an integral part of the total assembly system and communicates and directs the long-reach manipulators and jigging robots during assembly operations ensuring the final assembly achieves the accuracy and precision required to successfully execute the mission of the telescope. The module assembly is a repetitive process and there are no limits to the size of aperture that can be achieved. The long-reach manipulator and jigging robots would also deploy and attach the sun shield to the telescope, as well as deploy/construct any structures required to support secondary mirrors, instrument modules, etc.

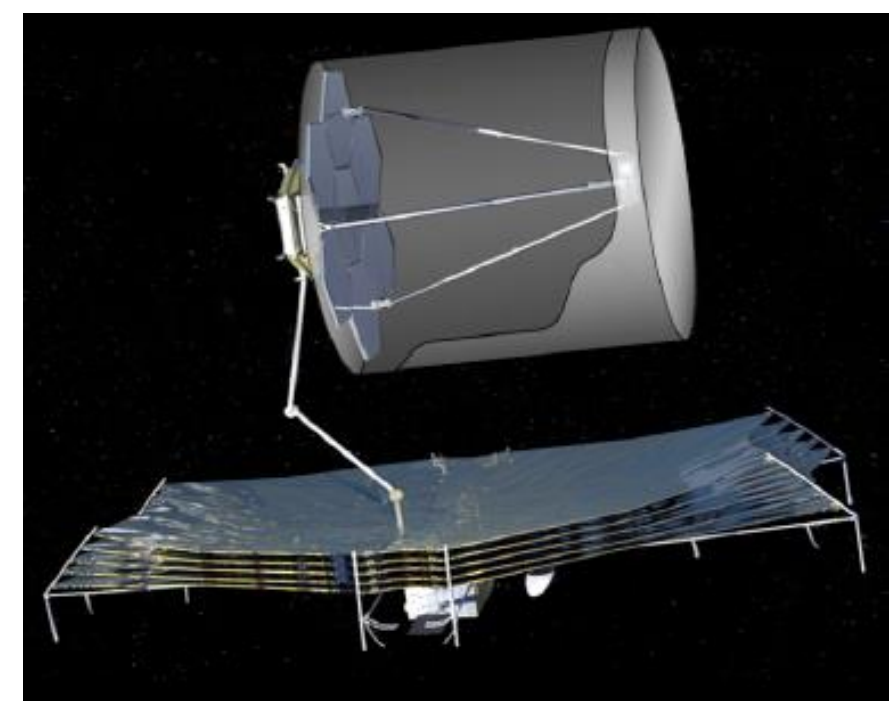

Figure 4. Example of large space telescope with sunshield.

\section{(3) Repairable, Replaceable, and Reusable Modules for EMC}

Challenges. The challenge is incorporating reusability and modularity into the EMC and defining those capabilities that would benefit EMC architectures, while simultaneously achieving the goal of developing multi-use, evolvable space infrastructure that minimizes the need to develop unique systems. One major area the architecture studies are currently focused on are concepts for a reusable propulsion module ${ }^{14}$. The propulsion system incorporates a hybrid architecture; that is, a combination of chemical and solar electric systems all in a single stage that is fully fueled on Earth departure. The major focus to date has been limited to propellant replenishment (fuel resupply) with two approaches being considered: 1) using a tanker vehicle to refuel the spacecraft (fluid transfer of propellants and pressurization gases) as depicted in Figure 5, and; 2) replacing empty tanks on the vehicle with new full tanks. There are many different challenges for each approach that include: approach, rendezvous and docking of servicing spacecraft; robotically connecting/disconnecting fuel lines; ensuring integrity of fuel-line connections; robotically manipulating, connecting and disconnecting large/massive fuel tanks; performing operations autonomously; minimizing the need for unique support infrastructure; and performing operations in a timely manner to meet mission departure dates. 


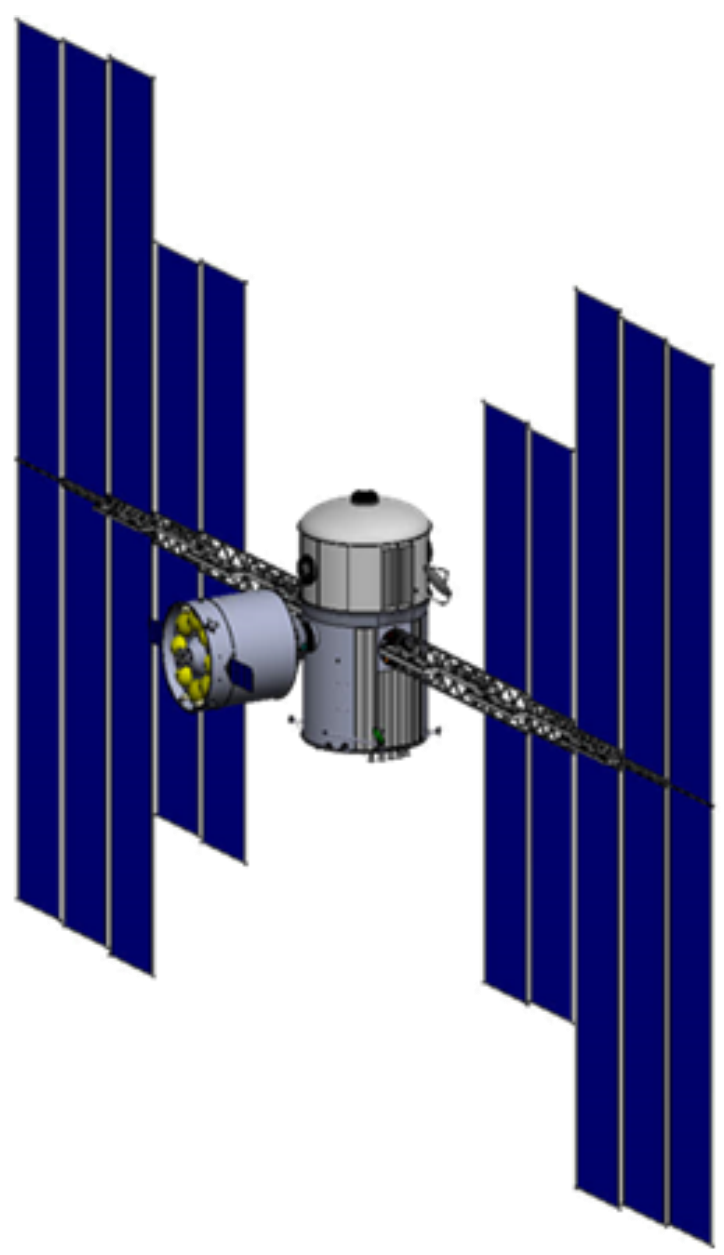

Figure 5. Example of Mars mission spacecraft being refueled.

On-Orbit Assembly Concept. At this time, descriptions of replenishment or replacement operations pertaining to the reusable propulsion module are only notional. For the refueling option; a tanker spacecraft must berth or dock to the Mars spacecraft; lines for the various fluids must be connected to the appropriate tanks and their integrity verified; fluids must be transferred; transfer fluid lines disconnected; and any other servicing or repair tasks performed. Versions of these operations have been performed in space during the Orbital Express mission ${ }^{21}$ and on the ISS with the GSFC satellite servicing experiments ${ }^{22}$. For the tank replacement option; the servicing spacecraft (which has two new full tanks) must berth or dock with the Mars spacecraft; the used tanks must be disconnected and staged/stored; each of the new full tanks must be manipulated into place and attached to the Mars spacecraft; integrity of the new connections validated; and any other servicing or repair tasks performed. All of the operations are assumed to be performed autonomously and robotically.

\section{Benefits From SALSSA Approach}


Many features and capabilities are associated with achieving a functioning spacecraft system in space. In this section, these features/capabilities are listed and their implementation in the traditional spacecraft architecture and the SALSSA architecture are discussed, as well as the benefits that accrue from using the SALSSA approach.

\section{Launch to Orbit.}

Traditional Implementation: Single launch which leads to spacecraft/mission mass and volume constraints, many conventional deployable systems, and potentially higher launch cost.

SALSSA Implementation: Modules can be launched individually, aggregated, and assembled on orbit.

Benefits from SALSSA Implementation: Can reduce and optimize launch cost for mission, relieve geometric constraints on spacecraft modules allowing increased performance (increased cross-section of a solar array backbone truss for example), and dramatically increase the performance of the final system (its size, power level, aperture area, etc.).

\section{Module Aggregation.}

Traditional Implementation: Except for assembly of the ISS, which relied on the Space Shuttle and its capabilities (long-reach robotic arm and EVA), this capability is not used.

SALSSA Implementation: For mission applications where the final spacecraft will be assembled from multiple modules launched separately, the modules must be aggregated at the assembly site. This would include the new module/spacecraft rendezvousing and berthing with the assembled spacecraft.

Benefits from SALSSA Implementation: As the amount of ISA increases, permanent supporting infrastructure might be established where aggregation would occur. This infrastructure would allow for the staging, pre-positioning and safe storage of arriving modules. The infrastructure could also serve as the permanent location for the assembly support systems such as long-reach manipulators, jigging robots, joining systems and measurement/metrology systems.

\section{Deployable Modules.}

Traditional Implementation: Spacecraft are assembled on the ground and launched as an integrated unit. Spacecraft can have a variety of deployable subsystems, such as solar arrays, thermal radiators, sun shields, and antennas/reflectors. The deployable systems can require very complex operations to transition from the packaged to deployed state due to packaging constraints. The deployable systems also tend to have a large number of joints, latches, motors, springs, and other mechanisms that add mass, compliance and mission risk. Many deployable beam $/ \mathrm{mast}$ concepts also require a heavy deployment canister. Packaging constraints can also severely limit the final spacecraft size and mission performance.

SALSSA Implementation: Deployable modules change the paradigm of spacecraft design because they allow the designer to take advantage of both pre-integration and ISA to optimize a particular mission. This versatility is demonstrated in the examples of module concepts developed for the Megawatt Solar Electric Tug and the Large Space Telescope.

The Large Solar Arrays for the Tug consist of a simple deployable backbone truss module that has periodic integration sites for deployable solar array wing modules. The primary aperture for the Large Space Telescope consists of a deployable support truss with integrated hexagonalpanel mirror segments that are pre-integrated (includes all of the power, electronics, and mirror positioning / control / actuation hardware). 
For both applications, no deployment motors, canisters, or springs are necessary; a robotic manipulator is used to deploy the modules. Small jigging robots could set and maintain the final structural precision while a long-reach manipulator would: lock/weld/bond any deployment hinges/joints, deploy the necessary backbone structure, and attach payload modules to that structure at appropriate stages of deployment.

Benefits from SALSSA Implementation: A Module will be defined taking into account factors such as; the mission application, ground-test facility capabilities, technology readiness of sub-module components (mirror segment size for telescope, as an example), mass, and volume capability of the launch vehicle. Modules can be defined based on optimizing the spacecraft performance and/or to minimize cost, mission risk, mass, or some combination of metrics. Benefits of the SALSSA approach include: reduced module structural mass, simplified module system design and integration, reduced cost and complexity, increase in system and mission reliability, and reusing the robotic infrastructure to assemble spacecraft for other missions.

\section{Modular Spacecraft Design and Design for Assembly.}

Traditional Implementation: Not applicable, launched as single integrated system.

SALSSA Implementation: Performance and mission requirements are optimized at the spacecraft level and then, the spacecraft is divided into individual modules where the modules are sized to meet launch mass/volume/packaging requirements. The modules could also be optimized such that they can fit into existing ground-based test facilities. In some cases, the mission spacecraft could be optimized to use pre-existing modules that have already been developed, such as solar arrays or mirror segments. For example, a very large aperture telescope could be assembled using the mirror segments already developed for JWST. By doing this, a very large aperture could be achieved without requiring new investment in mirror technology and the resulting expense and time that would incur.

Benefits from SALSSA Implementation: Ground testing cost and complexity can be dramatically reduced when a very large space system, that only has to function in zero-g, does not have to undergo full system level testing in one-g. Mission integrity can be assured by testing and verifying each individual module on the ground before flight, and by having the capability on orbit to perform servicing and repair functions. Reductions in total spacecraft mass and complexity can also be accrued because the entire spacecraft does not have to be designed to survive launch loads. It is likely much easier to design for launch loads in an individual module than for an entire spacecraft. Cost is reduced by using the same launch integration design for multiple modules. The performance constraints (diameter/area of a telescope primary aperture for example) are eliminated using the SALSSA approach. Launch costs can be minimized by shopping for the launch vehicle that has the lowest price in terms of dollars/pound to orbit. Mission cost can be reduced when multiple modules are fabricated (such as solar arrays) for a particular spacecraft. Further cost savings accrue when new missions begin to incorporate off-the-shelf heritage modules into their design. The modular approach can reduce mission risk and cost by allowing a spare module (as opposed to an entire spacecraft) to be built and launched and used in place of one that has failed. Finally, the modular approach allows for a spacecraft to be assembled and operated at an initial performance level, and then be upgraded incrementally in the future by adding modules.

\section{Reconfigurable Systems.}

Conventional Implementation: Not applicable, launched as single integrated system.

15john.t.dorsey@nasa.gov 
SALSSA Implementation: A key approach for enabling reconfiguration is to have a limited number (standard set) of reversible structural and utility, etc. joints at module interfaces; include adjustability in structural connections to achieve desired geometry and precision in the final assembled structure; and implement new joining methods into the connectors which could be mechanical connection, welded connection, bonded connection, etc.

Benefits of SALSSA Implementation: Reversible connections allow damaged modules to be replaced. As new capabilities are developed, old modules can be replaced with new ones having either higher/better performance, or new and different functions. These connections would also allow spacecraft to be taken apart and have modules repurposed for other uses or to serve in other systems. This attribute has the potential to reduce mission risk and cost, and increase mission life.

Autonomous Robotic Assembly Systems and Operations.

Conventional Implementation: Not applicable, launched as single integrated system.

SALSSA Implementation: Use a robotic assembly infrastructure that consists of the robotic hardware, such as long-reach manipulators, IPJRs, tools and end effectors, and autonomous systems to control the robots. Simple, small, reusable IPJRs would grapple, manipulate and set the precision between modules during structural joining. Lightweight general-purpose long-reach manipulators (with appropriate tools and end effectors) would be used to reposition IPJRs, manipulate and position modules for assembly, deploy modules, and make utility connections, etc. Since the robotic operations are likely to take place at many different locations in space, supervised autonomy will be the desired control mode. Planning and surveying systems that use vision and knowledge of the final spacecraft specifications will guide the IPJRs in setting module-to-module precision and aid the general-purpose robots in manipulation and joining operations. Metrology systems will perform final validation of the spacecraft geometry and configuration, while maintaining the ability to make any final adjustments before a spacecraft is released and begins mission operations.

Benefits of SALSSA Approach: Autonomous robotic operations will allow assembly to take place at a location that is best for the mission. For example, a large aperture space telescope could be assembled at its operational location at a Lagrangian point. Many space systems would no longer need a propulsion system for orbital transfer, but would only require what is necessary for station-keeping, pointing and slewing, etc., resulting in a reduction in the mission spacecraft mass, complexity, and cost. The robotic infrastructure would be reusable, so that no mission had to pay exclusively for the infrastructure design, development, manufacture, and launch. The robotic infrastructure could also be mobile so that repair, servicing and upgrade services could be called "on demand" by a mission.

\section{Measuring SALSSA Benefits (Metrics)}

In the preceding section, many benefits that might be incurred from using the SALSSA approach are discussed. Ultimately, these benefits must be measured and proven. This section describes some of the metrics, or figures of merit, that will need to be measured to ultimately prove the benefits of the SALSSA approach.

16john.t.dorsey@nasa.gov 
System cost is one figure of merit that needs to be captured. The goal of in-space infrastructure is to reduce the total system cost as well as the time and cost of assembling, servicing, repairing and reconfiguring individual spacecraft and space systems. For example, the modular assembly approach combined with supporting infrastructure, allows the spacecraft components needing transportation to low Earth orbit (LEO) to be divorced from specific launch vehicles, allowing the customer to shop for the lowest price launchers. The infrastructure can eliminate many precision, grappling, manipulating, etc. requirements from the spacecraft components, resulting in cost savings to the spacecraft. Versatile infrastructure could be accumulated on orbit over several missions and reused for subsequent missions, allowing the cost of the infrastructure to be amortized over many different vehicles, missions and systems.

The time required to put a space system into service is another figure of merit that should also be assessed. Using preexisting infrastructure to perform assembly, repair, and servicing, etc. operations in space, is likely to result in substantial time savings. The total time to enter a spacecraft or space system into service, as well as the total life cycle time to perform assembly, repair, and servicing, etc. operations should be measured.

Modularity and versatility of the infrastructure to support a diverse set of spacecraft and space systems that enable a variety of mission architectures is another figure of merit. Included here could be a metric on the number of unique infrastructure devices that would have to be designed, built, tested, and entered into service.

Risk reduction is another figure of merit. The infrastructure and its capabilities will allow for replacement or repair of defective parts during and after assembly of a vehicle or system. Final inspection and verification of all on-board systems before a vehicle enters service, and the capability to repair and replace components once in service also provides a substantial reduction in program risk. All of these capabilities reduce the requirements on the vehicle systems resulting in additional cost savings.

Total architecture mass launched to orbit is another figure of merit. Investing in infrastructure that can be reused repeatedly can reduce the mass of each spacecraft and space system being assembled, serviced, or repaired, etc. Thus, the total mass of an architecture that incorporates the use of on-orbit infrastructure can be substantially less than one that does not.

Performance metrics for the particular components and devices making up the infrastructure will be specific to each device. For example, performance metrics for robotic arms and manipulators should include; positioning accuracy, reach, dexterity, slew rate, positional stability (stiffness and damping), degree of redundancy (in function), etc.

\section{Cross-Cutting Technical Capabilities}

Based on the challenges and implementation/assembly concepts described for the three focus applications, a set of cross-cutting technical capabilities have been derived and are summarized in Table 5. An added benefit of these ISA capabilities is that they are versatile, not 
only enabling assembly, but also enabling repair, maintenance and refurbishment of space systems, as well as re-purposing spacecraft modules for new missions.

Table 5. Cross-cutting technical capabilities derived from focus applications.

\begin{tabular}{|l|c|c|c|}
\hline \multicolumn{1}{|c|}{ Technical Capability } & $\begin{array}{c}\text { Megawatt Solar } \\
\text { Electric Tug } \\
\text { Application }\end{array}$ & $\begin{array}{c}\text { Large Next- } \\
\text { Generation Space } \\
\text { Telescope } \\
\text { Application }\end{array}$ & $\begin{array}{c}\text { Repurposable } \\
\text { Modules for } \\
\text { Evolvable Mars } \\
\text { Campaign } \\
\text { Application }\end{array}$ \\
\hline Modularity and Aggregation & Yes & Yes & Yes \\
\hline Deployable Modules & Yes & Yes & Yes \\
\hline $\begin{array}{l}\text { Modular Interfaces and } \\
\text { Reversible Joining }\end{array}$ & Yes & Yes & Yes \\
\hline $\begin{array}{l}\text { Autonomous Robotic } \\
\text { Assembly Systems and }\end{array}$ & Yes & Yes & Yes \\
\hline $\begin{array}{l}\text { Operations } \\
\text { Opetrology and Assembly }\end{array}$ & Yes & Yes & \\
\hline
\end{tabular}

\section{SALSSA Enabling Technologies and Roadmaps}

Taking the cross-cutting capabilities listed in Table 5, together with the more detailed assembly approaches outlined for the three focus applications, a set of technologies that enable ISA can be developed. Efficient execution of these capabilities and functions will require supporting infrastructure and personnel, such as: EVA and Intra-Vehicular Activity (IVA) astronauts, robotic arms (teleoperated and autonomous), space manipulators, mobile bases and transporters, assembly and manufacturing fixtures (alignment, jigs, positioning aids), module/component storage, hangers and enclosures, workstation bases, etc. Supporting capabilities in inventory control, operations planning and simulations, verification and test protocols, and diagnostic software will be needed to safely and efficiently execute operations involving the infrastructure.

Many technologies are needed to enable efficient in-space robotic servicing, repair, assembly, and construction operations, including: manipulators that are dexterous, have long reach and are lightweight; modular interfaces with appropriate strength, stiffness, thermal stability, and reversibility; assembly worksites with fixtures and robotic jigging for precision assembly, and robotic operations and planning. These technologies in aggregate should be able to assemble high and low precision structures; assemble structures with a wide variety of sizes and geometries; reduce costs by using robotic infrastructure that is versatile and reusable, and; reduce spacecraft mass by using simple structure with efficient load paths. These technologies should also enable efficient, low cost, and versatile spacecraft repair and servicing operations as well as support other missions such as orbital debris removal and asteroid handling and capture.

Infrastructure design should occur concurrently with the space mission vehicle design to allow for optimum vehicles and systems. For example, designing capability into the infrastructure 
to perform precision alignment and controlled mating, docking, or assembly can dramatically reduce requirements in the vehicle hardware for making permanent connections. The infrastructure would also subsequently be able to perform the same functions in reverse, allowing for controlled disassembly for either repair, refurbishment, or to allow reconfiguration of systems into a new vehicle arrangement. Placing required capabilities in the infrastructure, where the capabilities can be used repeatedly to support many vehicles and systems, can dramatically reduce the cost of each mission. Much of the infrastructure and devices perform functions that are applicable to operations on-orbit as well as on planetary surfaces. As a result, commonality in design (taking into account various gravity levels), development, fabrication and testing is likely to be realized, leading to further program efficiencies.

Some of the technologies that could be developed to accelerate the use of ISA in new missions are summarized in Table 6.

Table 6. Technologies that enable SALSSA.

\begin{tabular}{|c|c|}
\hline Technical Capability & Enabling Technology Examples \\
\hline Modularity & $\begin{array}{ll}\text { - } & \text { Truss structural concepts } \\
\text { - } & \text { Robotically deployable concepts } \\
\text { - } & \text { Simple structural joints } \\
\text { - } & \text { Modular interfaces (robotically compatible) } \\
\text { - } & \text { Reversible joining } \\
\text { - } & \text { Mechanical (high strength, high stiffness, high thermal } \\
& \text { stability) joints } \\
- & \text { Electrical/data connections } \\
- & \text { Robotically compatible mechanical systems } \\
- & \text { Welding } \\
- & \text { Bonding }\end{array}$ \\
\hline Autonomous Operations & $\begin{array}{ll}- & \text { High precision sensing } \\
\text { - } & \text { Failure detection and correction } \\
\text { - } & \text { Integration with operations planning } \\
\text { - } & \text { Machine learning algorithms } \\
\text { - } & \text { Optimal action planning algorithms } \\
\text { - } & \text { Supervised autonomy }\end{array}$ \\
\hline Manipulation Systems & $\begin{array}{ll}\text { - } & \text { Long-reach manipulation: Tendon-Actuated Lightweight In- } \\
& \text { Space MANipulator (TALISMAN) } \\
\text { - } & \text { High-stiffness durable tendons } \\
\text { - } & \text { Intelligent Precision Jigging Robots (IPJRs) } \\
\text { - } & \text { Precision adjustment: } 6 \text { dof } \\
\text { - } & \text { Sensors } \\
\text { - } & \text { High precision actuators }\end{array}$ \\
\hline $\begin{array}{l}\text { Metrology and } \\
\text { Assembly Operations } \\
\text { Planning }\end{array}$ & $\begin{array}{ll}\text { - } & \text { Sensors and targets } \\
\text { - } & \text { Communications } \\
\text { - } & \text { Verification (as-built) software Sequence planning } \\
\text { - } & \text { Path planning } \\
\text { - } & \text { Robotic asset scheduling } \\
\text { - } & \text { Inspection and verification methods }\end{array}$ \\
\hline
\end{tabular}

19john.t.dorsey@nasa.gov 


\begin{tabular}{|l|l|}
\hline On-Site Infrastructure & - Spacecraft rendezvous support systems \\
& - Spacecraft berthing support hardware \\
& - Module staging/stowage support hardware \\
\hline
\end{tabular}

In order to generate SALSSA roadmaps, a review of potential future exploration missions and science decadal missions (which are discussed in previously cited documents) and the NASA technology roadmaps, was performed. Extracting information from the technology roadmaps, the EMC missions can be cross-referenced to Design Reference Missions (DRMs) 5 through 9 for planned/estimated mission launch and technology need dates. Similarly, the science missions are extracted from science decadal planning documents referenced in the NASA technology roadmaps.

The DRMs are listed in the technology roadmaps as:

DRM 5 Asteroid Redirect - robotic spacecraft (Extending reach beyond LEO),

DRM 5 Asteroid Redirect - crewed in Distant Retrograde Orbit (Into the Solar System),

DRM 6 Crewed to Near Earth Asteroid (Exploring other worlds),

DRM 7 Crewed to Lunar Surface (Exploring other worlds),

DRM 8 Crewed to Mars Moons (Exploring other worlds),

DRM 8a Crewed to Mars Orbital (Planetary Exploration),

DRM 9 Crewed to Mars Surface (Planetary Exploration).

The list of planned or proposed NASA science missions can be found in the Introductory Technology Roadmap as well. The science reference mission for the Large Next Generation Space Telescope Focus Application is based on the decadal planning for astrophysics, using need dates provided in the technology roadmaps for Exoplanet Direct Imaging Mission, Large UltraViolet/Visible/Infra-Red surveyor Mission, and the X-ray Surveyor Mission as the potential applications.

For the three Focus Applications, representative relevant technologies and their estimated earliest need dates specified in the technology roadmaps were compared and mapped to the need date of the focus mission to generate a SALSSA roadmap for each Focus Application. SALSSA technology elements that would be needed for assembling a megawatt-class solar electric tug are listed in Figure 6. The megawatt tug is indicated as being needed for the DRM $8-9$ missions (Mars moons and Mars surface) with technology need dates of 2023 and 2029, respectively. The NASA roadmap technologies that represent, or that could correspond to the technology elements, are listed along with their earliest indicated need date. While additional technology development may be needed for missions farther out in time, this mapping of technologies for the focus missions, versus the mission need dates, provides an initial estimate of when technologies could be available for demonstrations and where gaps in needed technologies may occur. The SALSSA technology elements for the Large Next Generation Space Telescope and the Reusable/Refurbishable Modules for EMC are mapped in Figures 7 and 8 respectively.

20john.t.dorsey@nasa.gov

Version 072016 


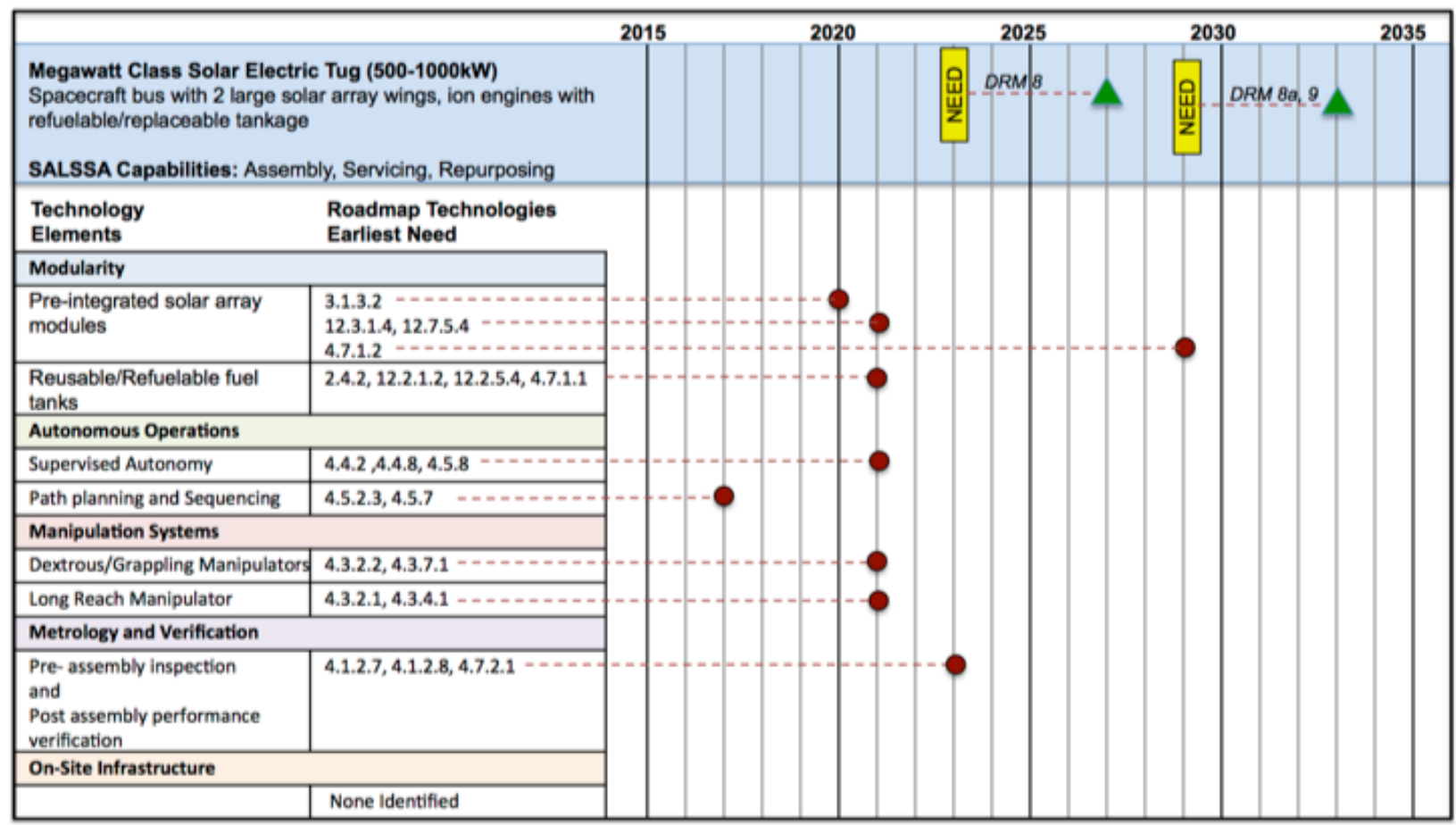

Figure 6. Megawatt Class Solar Electric Tug SALSSA Technology Elements Roadmap.

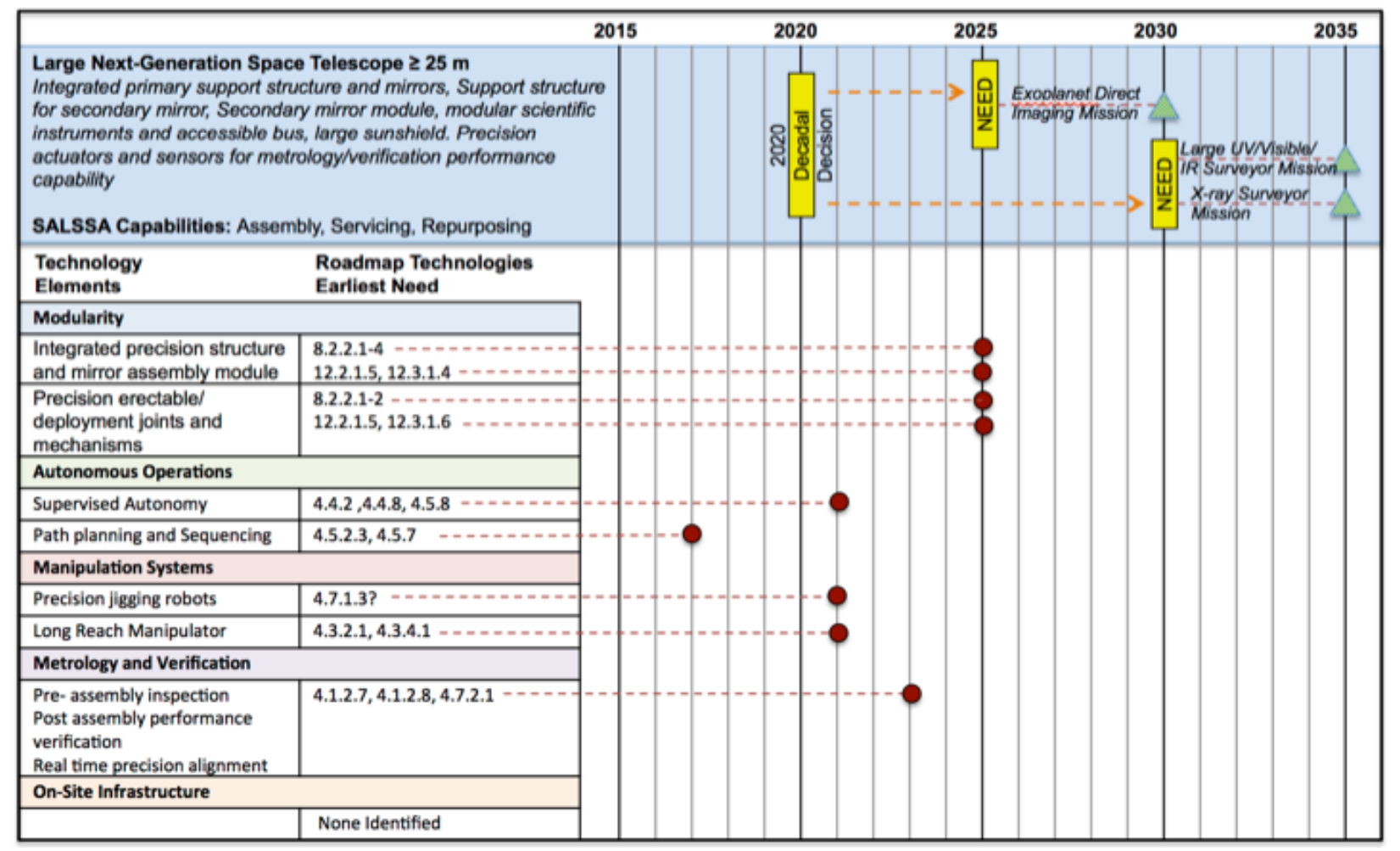

Figure 7. Large Next-Generation Space Telescope SALSSA Technology Elements Roadmap. 


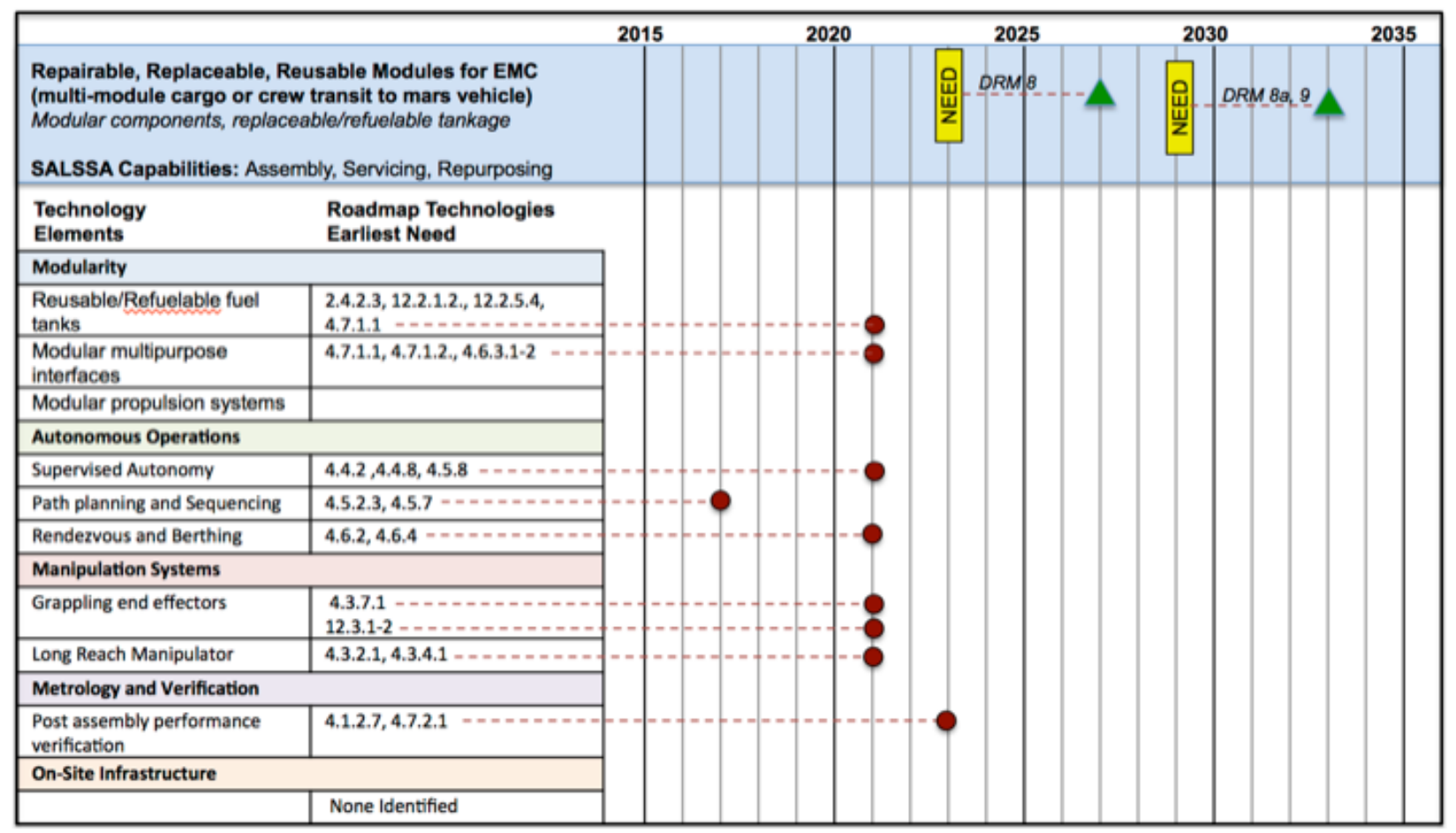

Figure 8. Reusable Modules SALSSA Technology Elements Roadmap.

\section{Summary}

Except for the International Space Station (ISS), all current spacecraft are transported to orbit as an integrated unit using a single launch. This launch posture severely constrains the mass and size of the spacecraft system because single launches must be designed to meet: the mass and volume constraints of the chosen launch vehicle, and the loads imposed by the launch environment. Developing a robust capability for Space Assembly of Large spacecraft Structural System Architectures (SALSSA) has the potential to drastically increase the capabilities and performance of future space missions and spacecraft while significantly reducing their cost. Currently, NASA Architecture Studies and Space Science Decadal Surveys identify new missions that would benefit from SALSSA capabilities, and technologies that support SALSSA are interspersed throughout fourteen NASA Technology Roadmaps. However, a major impediment to developing SALSSA technologies is the lack of an integrated and comprehensive compilation of the necessary information to enable strategic development of cross-cutting SALSSA technologies. This paper summarizes the results of a small study that had the goal of developing an integrated approach, which resulted in a cohesive roadmap and plan for SALSSA technology development. Three focus missions were defined that rely on SALSSA capabilities for viability. A set of Key Capability Areas were then defined along with a set of cross-cutting Technology Elements. The Technology Elements were mapped against the three focus problems and used to derive an example set of SALSSA enabling technologies that could form the basis of a technology development program. Finally, the Technology Elements were mapped into potential NASA missions related to the Focus Problems leading to a draft SALSSA-specific Technology Roadmap.

\section{References}


1. Gardner et. al., "The James Webb Space Telescope," Space Science Reviews, Volume 123, Number 4, 485-606, 2006.

2. "Reference Guide to the International Space Station, Assembly Complete Edition," NP-201009-682-HQ, Washington, D.C., November 2010,

3. Jorgensen, G., and Bains, E., "SRMS History, Evolution and Lessons Learned," AIAA 20117277, AIAA Space 2011 Conference and Exposition, Long Beach, California, Sept. 27-29, 2011.

4. Caron, M., and Mills, I., "Planning and Execution of Tele-Robotic Maintenance Operations on the ISS," SpaceOps 2012 Conference, Stockholm, Sweden, 2012.

5. Belvin, et. al., "In-Space Structural Assembly: Applications and Technology," AIAA-20162163, $3^{\text {rd }}$ AIAA Spacecraft Stuctures Conference, San Diego, California, USA, 2016.

6. Dorsey, J. T., Doggett, W. R., Hafley, R. A., Komendera, E., Correll, N., and King, B., “An Efficient and Versatile Means for Assembling and Manufacturing Systems in Space," AIAA2012-5115, AIAA Space 2012 Conference and Exposition, Pasadena, California, Sept. 11-13, 2012.

7. Douglas A. C., Herrmann, N. B., and Troutman, P. A., "The Evolvable Mars Campaign Study Status,” IEEE-2075, 2015 IEEE Aerospace Conference, March 7-14, 2015, Big Sky, Montana.

8. Bobskill et. al., "Preparing for Mars: Evolvable Mars Campaign 'Proving Ground' Approach," IEEE-2662, 2015 IEEE Aerospace Conference, Big Sky, Montana, March 7-14, 2015.

9. Committee for a Decadal Survey of Astronomy and Astrophysics; National Research Council,, "New Worlds, New Horizons in Astronomy and Astrophysics," Washington, D.C.: The National Academies Press, 2010.

10. Kouveliotou et. al., "Enduring Quests, Daring Visions (NASA Astrophysics in the Next Three Decades)," http://science.nasa.gov/media/medialibrary/2013/12/20/secureAstrophysics_Roadmap_2013.pdf, Dec. 16, 2013.

11. NASA Office of Chief Technologist, “2015 NASA Technology Roadmaps,” July 8, 2015. http://www.nasa.gov/offices/oct/home/roadmaps/index.html

12. Mercer, C. R., McGuire, M. L., Oleson, S. R., and Barrett, M. J., "Solar Electric Propulsion Concepts for Human Space Exploration,” AIAA Paper 2015-4521, 2015.

13. Feinberg, L. D., Budinoff, J., MacEwen, H., Matthews, G., and Postman, M., "Modular Assembled Space Telescope," SPIE Optical Engineering Journal, Vol. 52, No. 9, April 25, 2013, Special Section on Space Telescopes II.

14. Jefferies et. al., "Viability of a Reusable In-Space Transportation System," Presented at the AIAA Space 2015 Conference and Exposition, 31 Aug - 2 Sep. 2015, Pasadena, California. Available as AIAA-2015-4580.

15. Benedict, B. L., "Rationale for Need of In-Orbit Servicing Capabilities for GEO Spacecraft," AIAA- 2013-5444, Space Conference and Exposition, San Diego, California, Sept. 10-12, 2013.

16. Barnhart, D., Will, P., Sullivan, B., Hunter, R., and Hill, L., "Creating a Sustainable Assembly Architecture for Next-Gen Space: The Phoenix Effect," 30 ${ }^{\text {th }}$ Space Symposium, Colorado Springs, Colorado, May 2014. 
17. Erkorkmaz, C., Nimelman, M., and Ogilvie, A., "Spacecraft Payload Modularization for Operationally Responsive Space," $6^{\text {th }}$ Responsive Space Conference, Los Angeles, California, Apr. 28-May 1, 2008.

18. Troutman, P. A., et. al., "Orbital Aggregation and Space Infrastructure Systems (OASIS)," IAC-02-IAA.13.2.06, $53^{\text {rd }}$ International Astronautical Congress, Houston, Texas, Oct. 10-19, 2002.

19. Mikulas, M., Pappa, R., Warren, J., and Rose, G., "Telescoping Solar Array Concept for Achieving High Packaging Efficiency," AIAA-2015-1398, AIAA SciTech, Kissimmee, Florida, Jan. 5-9, 2015.

20. Hedgepeth, J. M., "Pactruss Support Structure for Precision Segmented Reflectors," NASA CR-181714, June 1989.

21. Boeing Company, "Orbital Express Program Summary and Flight Results," AIAA Space 2007 Conference and Exposition, Long Beach, California, 19-20 Sept. 2007.

22. Reed et. al., "The 'Master Enabler"' - In-Orbit Servicing, Presented at the AIAA Space 2015 Conference and Exposition, 31 Aug. - 2 Sept. 2015, Pasadena California, Available as AIAA-2015-4645. 